\title{
Effects of TiC content on microstructure and mechanical properties of nickel-based Hastelloy $X$ nanocomposites manufactured by selective laser melting
}

\author{
Quanquan Han ${ }^{a, b^{*}}$, Yuchen Gu$^{c}$, Liqiao Wang ${ }^{d^{*}}$, Qixiang Feng ${ }^{\mathrm{e}}$, Heng Guf ${ }^{\mathrm{f}}$, Richard \\ Johnston $^{c}$, Rossitza Setchi ${ }^{f}$
}

\begin{abstract}
aKey Laboratory of High Efficiency and Clean Mechanical Manufacture of Ministry of Education, Center for Additive Manufacturing, School of Mechanical Engineering, Shandong University, Jinan, 250061, China

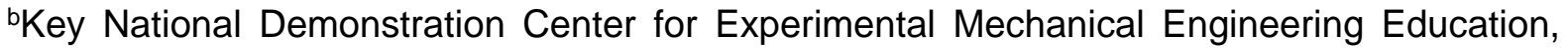
Shandong University, Jinan, 250061, China

'College of Engineering, Swansea University, Swansea, SA1 8EN, UK

${ }^{d}$ Cardiff Business School, Cardiff University, Cardiff, CF10 3EU, UK

eCollege of Mechanical Engineering, Chongqing University, Chongqing, 40044, China

${ }^{f}$ Cardiff School of Engineering, Cardiff, CF24 3AA, UK
\end{abstract}

\section{Corresponding authors:}

Quanquan Han, Hanquanquan@sdu.edu.cn, +86531-88392608

Liqiao Wang, Wangl45@cardiff.ac.uk,+447922067183

\begin{abstract}
The nickel-based Hastelloy $X(H X)$ superalloy is widely applied in the aerospace industry because of its exceptional oxidation resistance and various beneficial properties at high temperatures. HX-based nanocomposites manufactured by additive-manufacturing processes based on powder-bed fusion, such as selective laser melting (SLM), are expected to further enhance the material's mechanical and thermophysical performance. This paper systematically studies the effects of TiC nanoparticle content on the microstructure and tensile performance of SLM-fabricated $\mathrm{HX}$ nanocomposites. The results reveal that the microcracking that formed in pure $\mathrm{HX}$ was successfully eliminated in the fabricated nanocomposites when $1 \mathrm{wt} . \%$ and $3 \mathrm{wt} . \%$ TiC nanoparticles were introduced. The fabricated $\mathrm{HX}-3$ wt.\% (HX-3) TiC nanocomposite showed several TiC clusters and a much higher pore-volume percentage $(0.15 \%)$ compared to the $\mathrm{HX}-1$ wt.\% (HX-1) TiC nanocomposite, in which this percentage was determined to be $0.026 \%$. Compared to SLM-fabricated pure HX alloy, the HX-1 nanocomposite exhibited over 19\% and 10\% improvements in ultimate
\end{abstract}


tensile strength and elongation to failure, respectively. A further increase in TiC content to $3 \mathrm{wt} . \%$ was not found to further enhance the tensile strength but did result in a $10 \%$ loss in elongation to failure in HX-3 nanocomposite. These findings offer a promising pathway to employ SLM to manufacture both high-strength and high-ductility materials through the careful selection of nanoparticle materials and their content.

Keywords: Nickel-based superalloy; Hastelloy X; selective laser melting; additive manufacturing; nanocomposites; microcracking

\section{Introduction}

Hastelloy $X(\mathrm{HX})$ is a $\mathrm{Ni}-\mathrm{Cr}-\mathrm{Fe}-\mathrm{Mo}$ solid solution strengthened nickel-based superalloy that exhibits outstanding oxidation, corrosion resistance and strength at elevated temperatures [1]. For these reasons, HX has been widely employed in gas turbine engine combustors, petrochemical reactors and power-generation applications [2][3]. In additive-manufacturing processes based on powder-bed fusion, such as selective laser melting (SLM), a high-power laser is employed to manufacture metallic components with complex geometries through a layer-by-layer manufacturing principle [4][5][6][7]. Given the acceptable weldability of HX alloy, the SLM of HX alloy offers a promising pathway to fabricate high-performance HX components.

In recent years, researchers have investigated both the microstructure and mechanical properties of HX alloy manufactured by SLM technology. For instance, Tomus et al. [8] studied post heat treatments on the anisotropy of various mechanical properties of SLM-fabricated HX. They found that the yield strength was reduced by $200 \mathrm{MPa}$ after heat treatment due to the rearrangement of dislocations in the subgrain boundaries. Montero-Sistiaga et al. [9], who investigated the effects of a highpower laser on the microstructure and mechanical performance of manufactured $\mathrm{HX}$ components, found that the high-power laser ( $400 \mathrm{~W}$ ) they employed led to a coarser microstructure and induced a stronger morphological and crystallographic texture. Even under the optimal manufacture condition, however, the authors detected microcracks in the as-fabricated samples. In general, these microcracks can be closed by employing a hot isostatic pressing (HIP) post treatment, but in that study, the use 
of HIP also resulted in over $200 \mathrm{MPa}$ losses in yield strength. Marchese et al. [10], who studied the microstructure and cracking mechanism of SLM-fabricated HX alloy, demonstrated that the intergranular carbides, together with thermal residual stress, contributed to the formation of microcracks.

The aforementioned studies indicate that microcracking is the primary defect that occurs in the SLM of HX alloy. Microcracking significantly degrades HX's mechanical performance, as it acts as a fracture initiator, resulting in the material's brittle fracturing at low stress levels.

Metal matrix nanocomposites (MMNCs) are metal matrix composites (MMCs) in which nanoparticles are employed as the reinforcement phase. Due to their nanoscale structure, MMNCs exhibit an advantage over MMCs with microscale reinforcements in terms of improved wear resistance, damping properties and mechanical strength, thus making them more attractive for various applications [11][12][13][14]. Given these reasons, researchers have successfully used SLM technology to manufacture various nickel-based nanocomposites, such as TiC/Inconel 718 nanocomposites [15][16], carbon nanotube/Inconel 625 composites [17] and TiN/Inconel 718C composites [18]. Their findings have revealed that, compared to as-fabricated matrix materials, SLMfabricated nanocomposites exhibit higher tensile strength but lower elongation due to the ensuing grain refinement.

Although researchers anticipate that the SLM of HX-based nanocomposites offers great potential for manufacturing high-performance $\mathrm{HX}$ nanocomposite components with complex geometries, few studies of this potential have been conducted to date because of the significant microcracking that occurs. Previous studies have suggested that microcrack density can be reduced by reducing the content of the Mn and Si elements in HX alloy. This reduction has been found to improve tensile strength, although microcracks still cannot be eliminated [19]. While post-processing treatments such as HIP are reportedly capable of closing the microcracks in fabricated HX components, the HIP process results in a significant degradation of tensile strength caused by grain growth within the heat-treatment process. Studies have shown the 
reduction in yield strength to be up to $20 \%$, although a $15 \%$ increase in elongation to failure is reportedly achievable [8][9]. As a widely used ceramic reinforcement phase, TiC has also been employed in the SLM of stainless steel-based and titanium-based composites through either the ex-situ or in-situ method [20][21][22][23][24]. Their findings indicated that TiC reinforcement played a significant role in the mechanical properties' enhancement. The mixing method used in the aforementioned studies is ball milling process, which is capable of dispersing the TiC particles amongst the matrix powder but this mixing process could also change the particles' shape and damage their crystallographic structures due to the generated intensive impact. The mixing method used in the present work, however, is a high-speed mixing technique which allows to mix HX and TiC particles under a rotation speed over $1500 \mathrm{rpm}$ without the addition of extra milling balls.

In one previous study by the authors, microcracking was successfully eliminated by introducing $1 \mathrm{wt} . \%$ TiC nanoparticles in HX feedstock material (supplied by LPW Technology, UK) [25]; the addition of $1 \mathrm{wt}$ \% TiC nanoparticles also contributed to a 98 $\mathrm{MPa}$ increase in yield strength without undue sacrifices to ductility. A further increase in TiC reinforcement content could potentially enable further enhancement in the mechanical performance of SLM-fabricated HX nanocomposites. TiC nanoparticles are prone to agglomeration when the content is beyond the threshold, however. The agglomerated nanoparticles could function as stress-concentration sites and accelerate the nanocomposites' failure at low stress levels.

In this context, the present study systematically investigates the effect of TiC nanoparticle content on the microstructure and mechanical performance of SLMfabricated HX nanocomposites. The study also examines the effects of TiC reinforcement on microcracking elimination and strength enhancement. The aim is to develop an improved understanding of the additive manufacturing of advanced nickelbased nanocomposites and to provide practical insights into the selection of nanoparticle-reinforcement content in order to manufacture both high-strength and high-ductility nanocomposites. 


\section{Materials and methods}

\subsection{Feedstock powder and the selective laser melting process}

The raw gas atomised Hastelloy $X(H X)$ powder used in this work was supplied by Sandvik Osprey (Neath, UK), with an alloying composition (wt.\%) of 22.2Cr-19.1Fe8.9Mo-2Co-0.13C-0.7W-0.18Si-0.17Mn-bal. The average particle size was measured to be $32.5 \mu \mathrm{m}$. The majority of the HX particles had a spherical shape suitable for additive manufacturing even after several rounds of recycling, while some were observed to be imperfect (Fig. 1a-b). Typical imperfect $\mathrm{HX}$ particles were those coated with lump-like structures that had been partially melted in previous melting processes and then successfully recycled. In general, imperfect particles may affect mixing with TiC nanoparticles, because the lump-like structures could trap the TiC nanoparticles and form clusters.

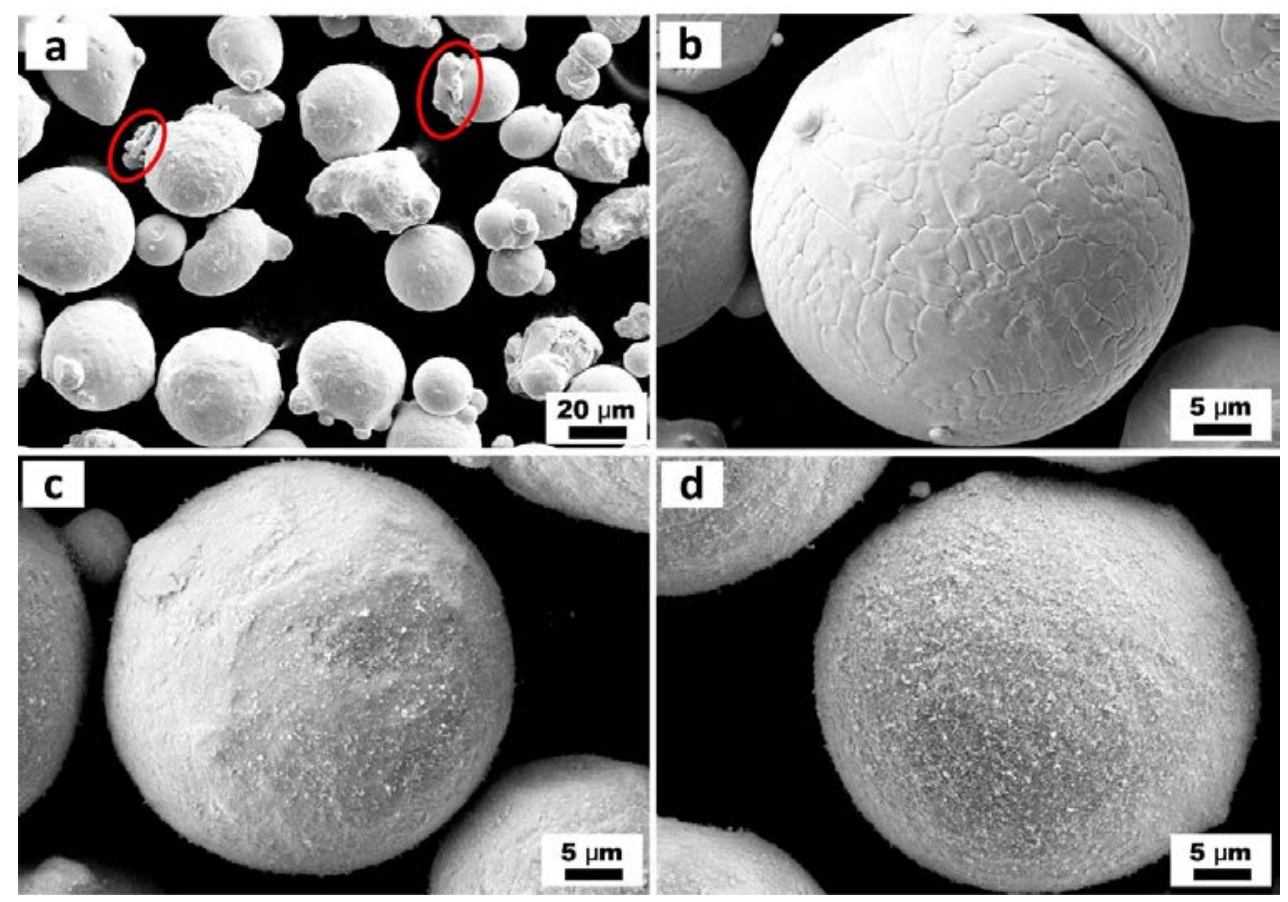

Fig. 1. The raw materials used for this study: (a)-(b) pure Hastelloy $X(H X)$ powder with different magnifications, red circles showing the particle shape imperfection; (c) HX with 1 wt.\% TiC nanocomposite powder; (d) HX with 3 wt.\% TiC nanocomposite powder.

The TiC nanoparticles $(<200 \mathrm{~nm}$ ) used in this work were obtained from Sigma Aldrich (UK). Fig. 1c and 1d show the mixed nanocomposite powder with $1 \mathrm{wt} . \%$ and 3 wt.\% TiC nanoparticles, respectively. Typical high-speed mixing parameters included 
a mixing speed of 1,200 rpm and a mixing time of $5 \mathrm{~min}$. More detail about the highspeed mixing may be found in a previous study [25]. The TiC nanoparticles were uniformly coated on the surface of the $\mathrm{HX}$ powder without settling after the mixing. As expected, the HX-3 wt.\% (HX-3) TiC nanocomposite feedstock powder was observed to offer a higher density of TiC nanoparticles compared to the HX-1 wt.\% (HX-1) TiC feedstock powder.

A Renishaw AM 250 system equipped with a modulated ytterbium-fibre laser was used in this work to manufacture the pure $\mathrm{HX}, \mathrm{HX}-1$ and $\mathrm{HX}-3$ nanocomposite specimens. The cubic samples $\left(8 \times 8 \times 8 \mathrm{~mm}^{3}\right)$ were fabricated to optimise the typical process parameters, such as laser-scanning speed and hatch spacing, while the laser power and layer thickness were fixed at $200 \mathrm{~W}$ and $40 \mu \mathrm{m}$, respectively. The optimal process parameters were then employed to manufacture a few cubic samples and tensile specimens that had been designed based on the ASTM-E8/E8M-13a guidelines to investigate the effect of TiC content on the microstructure and mechanical performance of the as-fabricated nanocomposites.

\subsection{Material characterisation techniques}

The cubic samples were vertically sectioned and polished based on standard polishing procedures prior to optical microscopy (OM) and scanning electron microscopy (SEM) inspection. The samples were subjected to electrochemical etching in oxalic acid for 10-15 seconds to reveal the molten-pool boundaries and solidification structures. Backscattered electron (BSE) SEM and electron backscatter diffraction (EBSD) analysis were performed using a high resolution Jeol 7800F FEG-SEM equipped with an Oxford Instruments AZtec EBSD system, to study the microstructure evolution and grain crystallographic orientations, while phase identification was analysed using X-ray diffraction (XRD) with $\mathrm{Cu} K$ radiation at $40 \mathrm{kV}$ and $100 \mathrm{~mA}$. Transmission electron microscopy (TEM) inspection was performed with an FEI Titan Themis 80-300 equipped with two aberration correctors and a highly efficient (fourquadrant) energy-dispersive X-ray (EDX) system to further investigate the microstructure of the as-fabricated samples. A Zeiss Xradia 520 Versa 3D X-ray micro- 
computed tomography (CT) microscope was used to view internal defects within a sampling volume of $1.45 \times 1.45 \times 1.45 \mathrm{~mm}^{3}$. The defects were reconstructed and visualised from the CT dataset using a commercially available software package Thermo Scientific ${ }^{T M}$ Avizo_2019.4. The minimum pore size detected in the CT scans was 3 voxels, equivalent to $2.9 \mu \mathrm{m}$ in diameter. However, any defects with diameter less than $3.6 \mu \mathrm{m}$ were deliberately eliminated in the post CT data analysis to reduce the noise. Uniaxial tensile testing was performed using a Zwick/Roell tester with a strain rate of $1.33 \times 10^{-3} \mathrm{~s}^{-1}$ at room temperature.

\section{Results and discussion}

\subsection{Defects evolution}

Fig. 2 shows the measured relative density of the as-fabricated pure HX, HX-1 and HX-3 nanocomposite samples versus laser-energy density (LED). The relative density for each sample was determined by measuring the sample three times and then averaging the values based on Archimedes method. The LED $(\varepsilon)$ was correlated to the laser power $(P)$, scanning speed $(v)$, hatch spacing $(h)$ and powder-layer thickness ( $t$ ) employed in the study; LED can be expressed as $\varepsilon=P /(v \cdot h \cdot t)$ [26][27]. The three materials showed a similar trend, where the relative-density values rose with an increase in LED until maximum relative density was achieved. The relative density was reduced afterwards with further increasing of the LED due to insufficient energy input. The optimal LED, however, was found to have significantly risen from an increase in $\mathrm{TiC}$ reinforcement in order to produce the nearly full-density samples. The determined optimal LED values to manufacture pure $\mathrm{HX}, \mathrm{HX}-1$ and $\mathrm{HX}-3$ nanocomposites were found to be 52,83 and $125 \mathrm{~J} / \mathrm{mm}^{3}$, respectively.

The significant increase in LED was attributable to the change in thermophysical properties on the feedstock materials induced by TiC additions. Previous studies have demonstrated that added ceramic reinforcement enhances the laser absorption of the nanocomposite feedstock powder due to the increase of powder-surface roughness, such that a lower LED is generally required to fabricate full-density components compared to matrix materials [28][29]. The added ceramic phase coated on the 
surface of the metal powder, however, also degrades the effective thermal conductivity of the nanocomposite powder because of the increased interfacial thermal resistance [30]. A higher laser-energy density is thus required to process nanocomposite materials. Our findings indicate that the added TiC nanoparticles played a more significant role in affecting thermal conductivity compared to laser absorption, because the optimal LED rose because of an increase in TiC reinforcement content.

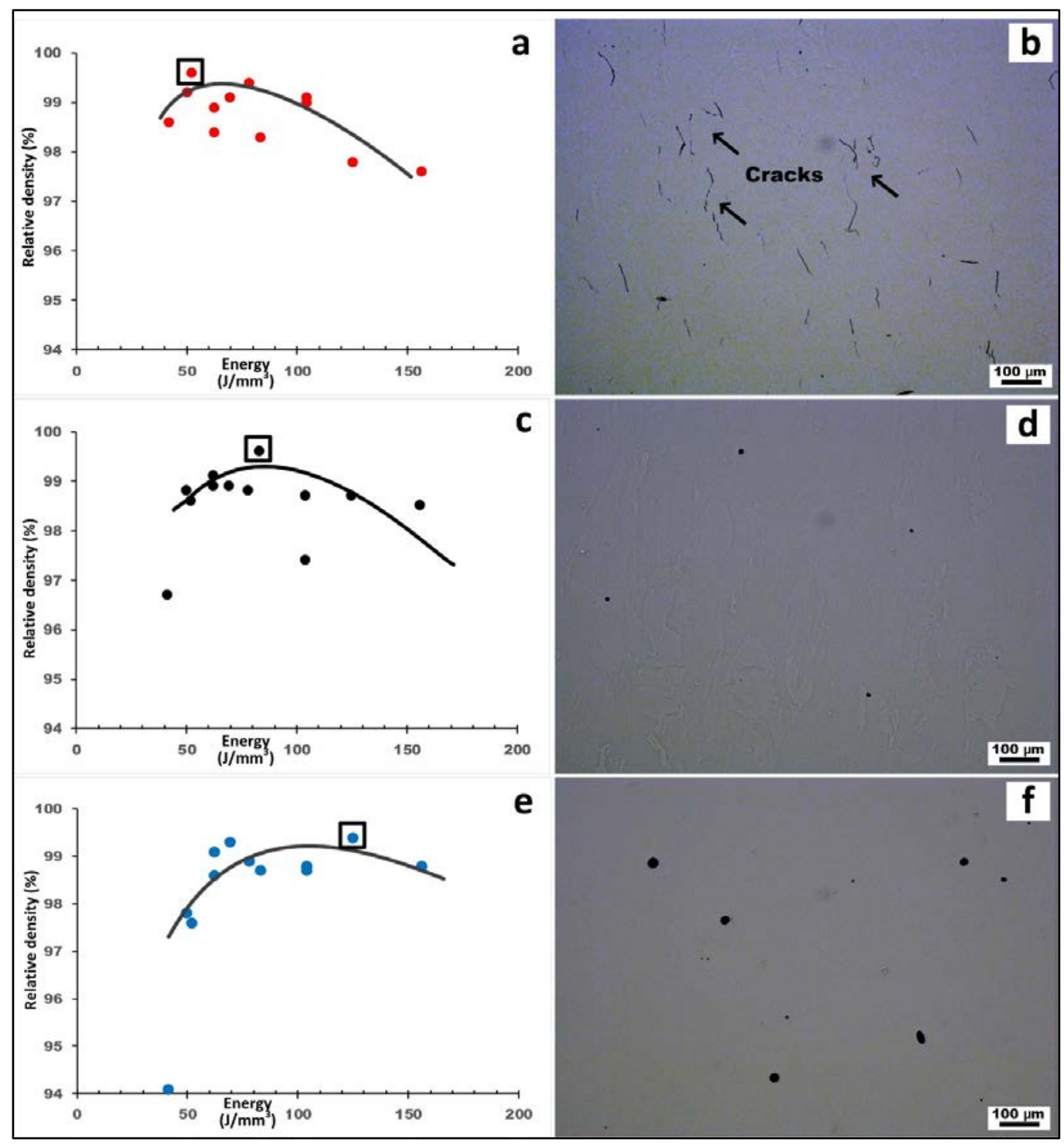

Fig. 2. Measured relative density versus laser-energy density and optical microscopy (OM) images under optimal conditions: (a)-(b) pure HX alloy; (c)-(d) HX-1 wt.\% TiC nanocomposite; (e)-(f) HX-3 wt.\% TiC nanocomposite material.

Our study's OM inspection showed that microcracks were the primary defects in the as-fabricated pure HX, even under the optimal condition (Fig. 2b), while only open pores were detected in both HX-1 and HX-3 nanocomposites (Fig. 2d/f). The average 
density of the microcracks found in pure $\mathrm{HX}$ was measured to be $0.6 \%$ (based on relative-density measurements), with sizes ranging from a few micrometres to over 100 micrometres. The open pores in the HX-3 nanocomposite were detected to be much larger than those found in HX-1 nanocomposite, which may be explained by the agglomeration of TiC nanoparticles in $\mathrm{HX}-3$ nanocomposite. Larger pores thus formed at the interface of the HX matrix and the TiC clusters.

Interestingly, some other studies that have reported the crack-free microstructure of SLM-fabricated pure HX include those by Sanchez-Mata et al. [31], Esmaeilizadeh et al. [32] and Keshavarzkermani et al. [33]. Although the employed laser power and scanning speed varied between the literature and current study, the microcracks were observed under all manufacture conditions in current study. This situation suggests that the employed process parameters might not be the crucial factors to determine the formation of microcracks. The chemical composition, in particular, the content of the minor alloying elements (e.g. Si, Mn and C) is considered to be the primary factor for hot cracking [7][34]. For instance, the content of $C$ element in the present study was measured to be $0.13 \mathrm{wt} . \%$ while the content in the literature was less than 0.06 wt.\%. A higher $\mathrm{C}$ element content is generally associated with a higher amount of carbide phase after the rapid solidification within SLM process; the carbides are more prone to hot tearing. The difference in minor alloying elements content may be the main contributor to microcracks that were observed in this study while they were not inspected in the literature. 


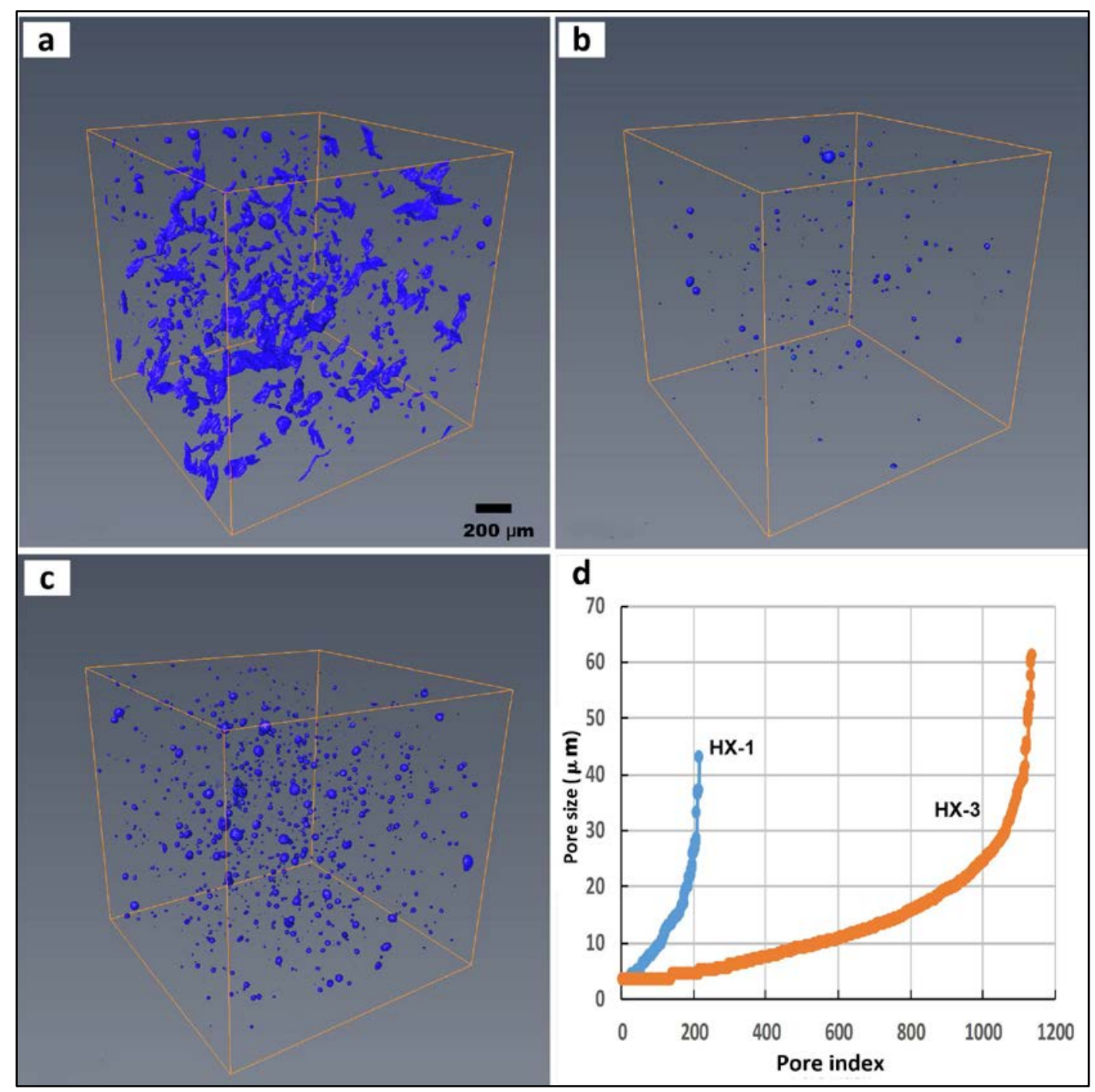

Fig. 3. Reconstructed micro-CT images of the as-fabricated bulk samples: (a) pure $H X$ alloy; (b) HX-1 wt.\% TiC nanocomposite; (c) HX-3 wt.\% TiC nanocomposite; (d) pore size versus index in the two composite samples.

Fig. 3 shows reconstructed micro-computed tomography (CT) images of the asfabricated samples manufactured under optimal conditions. The micro-CT examination confirmed that irregular microcracks were the primary defects to occur within the SLM of pure HX alloy; the defect-volume percentage was determined to be $0.67 \%$ (Fig. 3a). The pore-volume percentages in $\mathrm{HX}-1$ and $\mathrm{HX}-3$ nanocomposites samples were found to be $0.026 \%$ and $0.15 \%$, respectively, while no microcracks were detected in the two materials, thus confirming the elimination of microcracking induced by the addition of TiC nanoparticles (Fig. 3b-c). We should note that the extra 2 wt.\% TiC nanoparticles added in the HX-3 nanocomposite resulted in a significant difference in pore size and quantity compared to the HX-1 nanocomposite: around 210 open 
pores were detected in the HX-1 nanocomposite, with most less than $30 \mu \mathrm{m}$ in diameter. More than 1,100 open pores formed in the HX-3 nanocomposite samples, more than 100 of which were greater than $30 \mu \mathrm{m}$ in diameter (Fig. 3d).
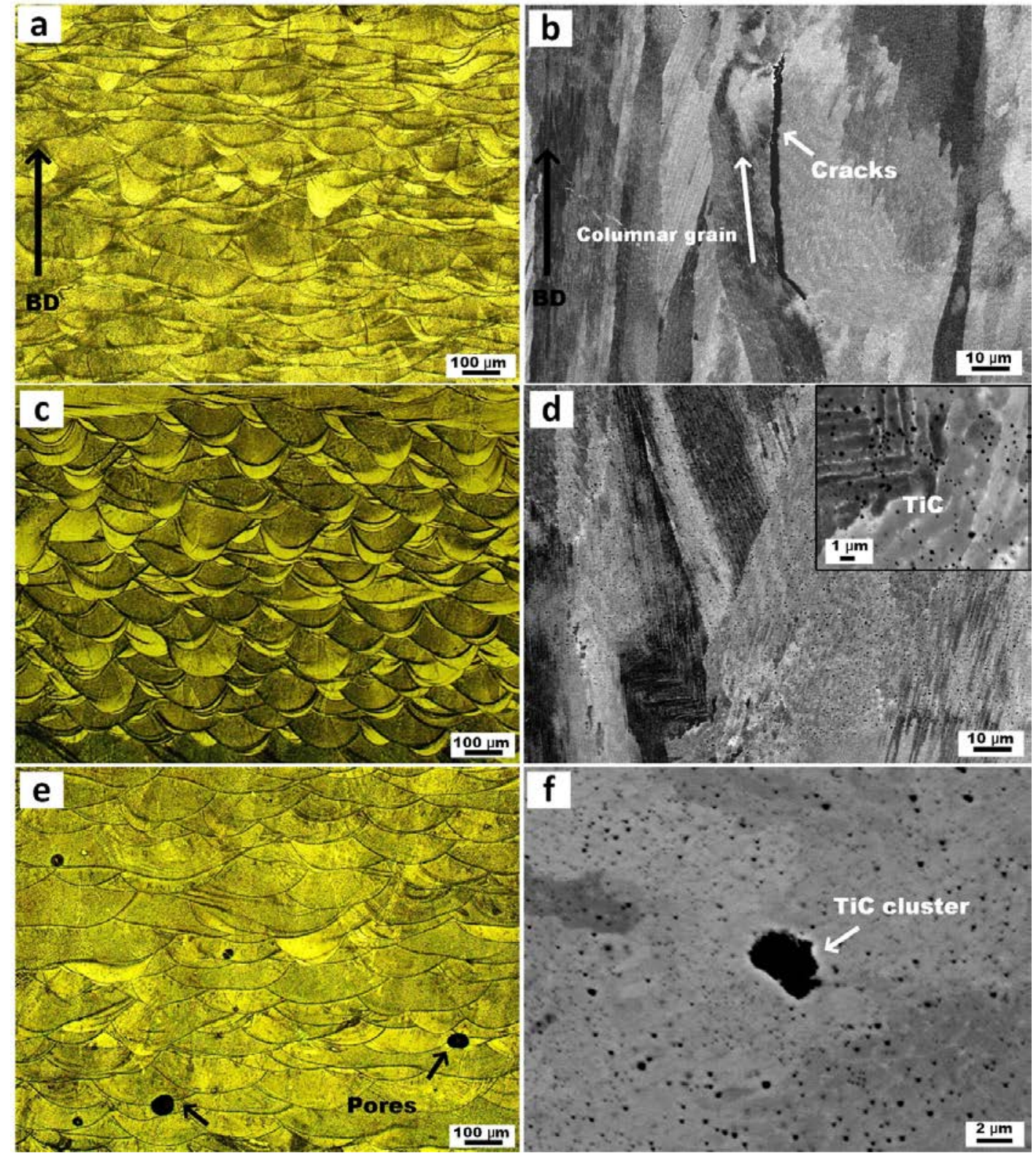

Fig. 4. Molten-pool features and microstructure of the as-fabricated samples under optimal manufacture conditions: (a)-(b) pure HX alloy; (c)-(d) HX-1 wt.\% TiC nanocomposite; (e)-(f) HX-3 wt.\% TiC nanocomposite material.

Fig. 4 shows the molten pools and microstructure of as-fabricated pure HX, HX-1 and HX-3 nanocomposites specimens under optimal manufacture conditions. Typical columnar grains along the build direction formed in the pure HX alloy, while the molten pools that formed during the SLM process were not observed to have uniform shapes 
even under the optimal conditions (Fig. 4a-b). The microcracks were distributed along the grain boundaries, indicating that they were intergranular cracks after rapid solidification had occurred. Previous studies have demonstrated that element precipitation and residual thermal stress are the primary contributors to microcrack formation in the additive manufacturing of nickel-based superalloys [9][10][35]. In general, microcracks can significantly degrade mechanical performance and shorten the lifetime of $\mathrm{HX}$ components, as the microcracks may function as brittle fracture initiators and result in failure at low stress levels.

Compared to pure $\mathrm{HX}$ alloy, the as-fabricated $\mathrm{HX}-1$ nanocomposite examined in the present study had no microcracks detected, suggesting the added $1 \mathrm{wt} \%$ TiC nanoparticles enabled the elimination of microcracks under the OM inspection (Fig. 4c). The BSE-SEM inspection confirmed the elimination of microcracks, even though columnar grains also formed in the HX-1 nanocomposite (Fig. 4d). Note that the added TiC nanoparticles were uniformly distributed in the HX matrix, which implies that the Marangoni stress caused by temperature gradients tended to disperse the TiC nanoparticles rather than agglomerating them to form clusters.

A much higher LED $\left(125 \mathrm{~J} / \mathrm{mm}^{3}\right)$ was required to fully melt the $\mathrm{HX}-3$ nanocomposites within the SLM process. The OM inspection has indicated that a few open pores formed even under the optimal manufacture condition; the open pores were randomly distributed inside the molten pools and along the fusion boundaries (Fig. 4e). The difference in optimal LED values confirmed that the increase in TiC content was more influential on thermal conductivity compared to laser absorption in the SLM of HX-TiC nanocomposites. The BSE-SEM confirmed that TiC clusters formed in the as-fabricated HX-3 nanocomposite samples that were not detected in the HX-1 nanocomposite samples (Fig. 4f). The TiC clusters were formed partially because the Marangoni stress was not strong enough to disperse the $3 \mathrm{wt} . \%$ TiC nanoparticles within the molten pools. Another contributor may have been the lumplike structures that coated the imperfect $\mathrm{HX}$ particles, which trapped the TiC nanoparticles into forming clusters after the powder mixing. The clusters were not dispersed after rapid solidification. 


\subsection{Phase identification and microstructure}

Fig. 5 shows the XRD patterns of the feedstock powder material and different SLM-fabricated materials under optimal manufacture conditions. The phase of the added TiC nanoparticles was detected in the HX-3 nanocomposite feedstock powder but not in the as-fabricated HX-3 nanocomposite bulk samples. The TiC phase was not identified in the bulk samples through XRD which is very likely due to the low content and fine size of TiC nanoparticles. The typical peaks of the face-centred cubic (FCC) austenite phase were clearly observed in all the as-fabricated bulk samples. Given that XRD inspection has a relatively low-resolution limit, high-resolution EDX and TEM examinations were conducted to further investigate the phases and microstructures of these samples.

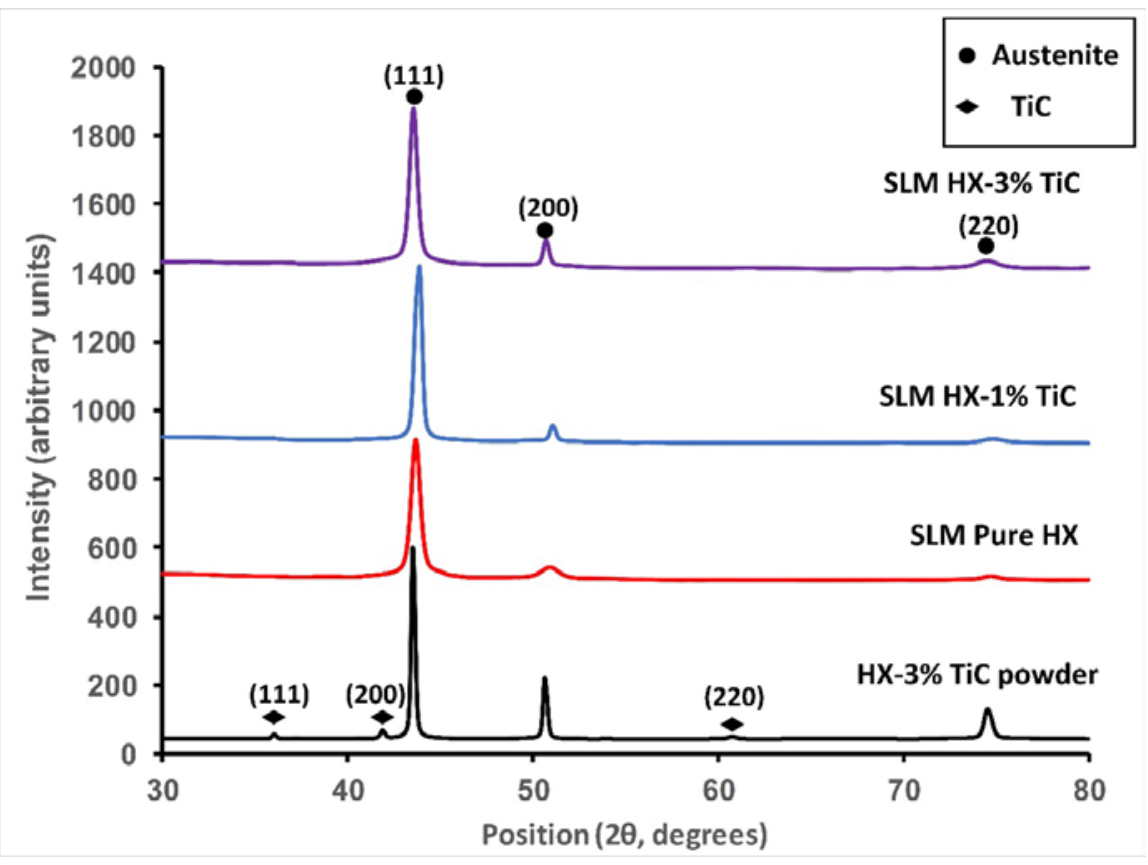

Fig. 5. X-ray diffraction (XRD) patterns for the feedstock powder material and different SLMfabricated material samples under optimal conditions.

Our TEM investigation revealed that element segregation occurred in all the fabricated bulk samples distributed along the columnar walls that had formed and that this segregation was not particularly affected by the addition of TiC nanoparticles. An EDX line-scan analysis of the HX-3 nanocomposite sample is shown in Fig. 6. The length of the scanned line was $680 \mathrm{~nm}$, and the line's midpoint was marked using 1 for reference. As the figure shows, the precipitate phase (marked as A1 in Fig. 6a) was 
analysed to be $\mathrm{Cr}$ - and Mo-rich carbide, while the $\mathrm{A} 2$ area was rich in TiC nanoparticles. The precipitated carbides and uniformly distributed TiC nanoparticles were expected to enhance the tensile strength of the fabricated components by pinning the dislocations' motion.

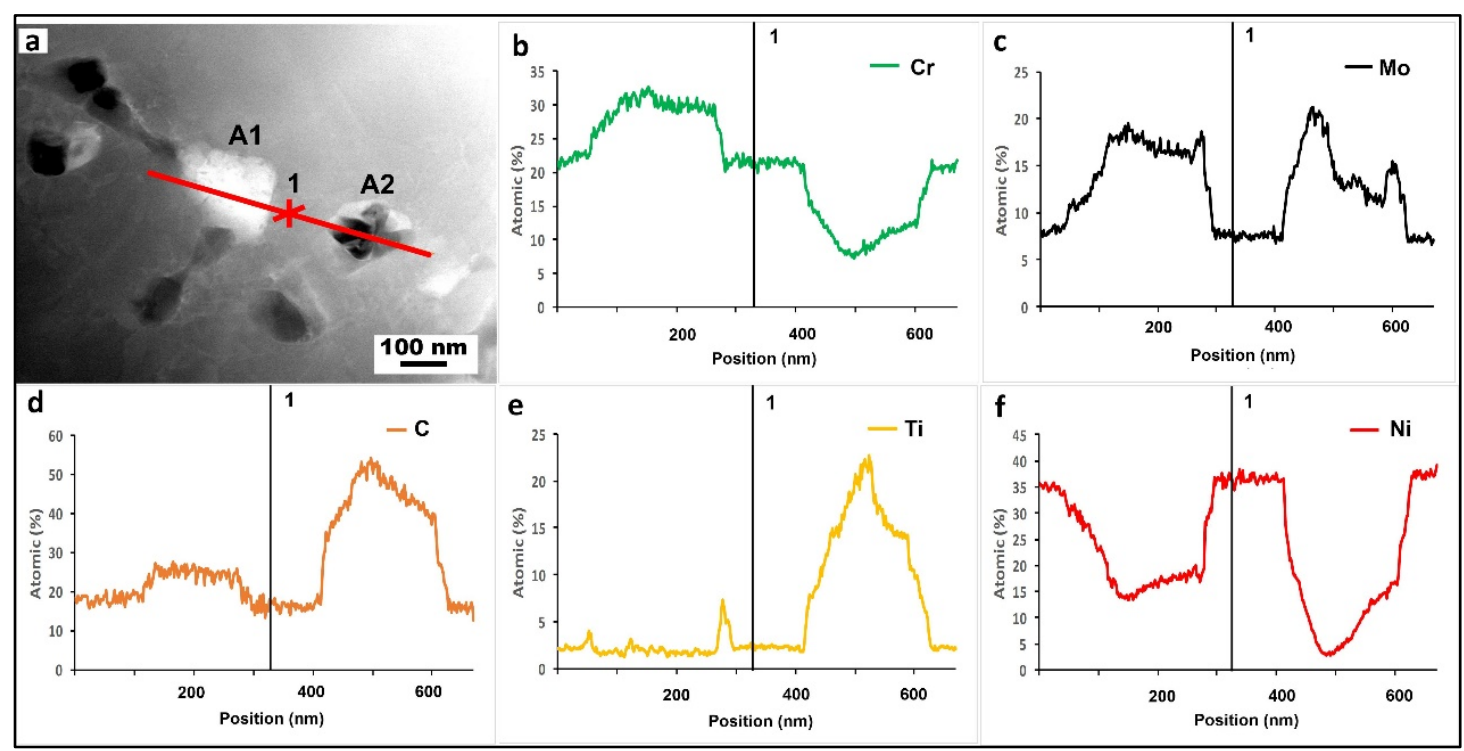

Fig. 6. EDX line-scan analysis for the fabricated bulk HX-3 wt.\% TiC sample.

To further identify the chemical composition of the precipitates, selected area electron diffraction (SAED) was conducted on the fabricated bulk HX-3 nanocomposite sample, as shown in Fig. 7. The irregular precipitates that formed were clearly observed along the solidified columnar walls (Fig. 7a), and the EDX point analysis also revealed that the irregular precipitates were rich in Mo and $\mathrm{Cr}$ elements. Our SAED analysis further confirmed that the precipitated carbide was $\mathrm{M}_{23} \mathrm{C}_{6}$ rather than $\mathrm{M}_{6} \mathrm{C}$ (Fig. 7c). Finally, the SAED analysis confirmed that the uniformly distributed nanoscale particles amongst the HX matrix were TiC nanoparticles (Fig. 7d-f). We should note that the addition of TiC nanoparticles did not affect element-segregation behaviour, but the microcracks that were formed in pure HX were successfully eliminated in the asfabricated HX-1 and HX-3 nanocomposites samples, which implies that the added 1 wt. $\%$ and $3 \mathrm{wt} . \%$ TiC reinforcements were more likely to have altered the residual thermal-stress distribution to eliminate microcracking. 

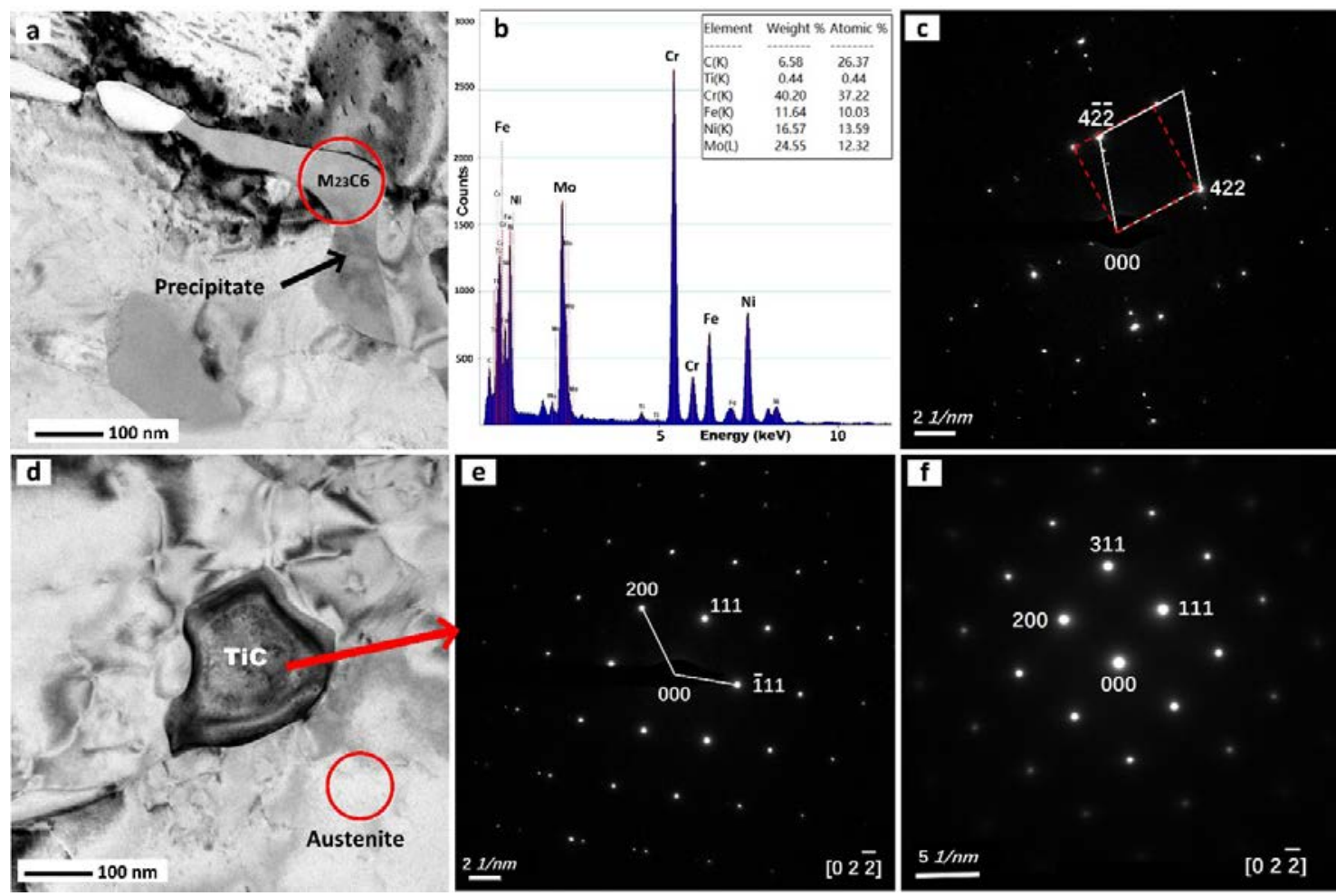

Fig. 7. Bright-field TEM images and corresponding SAED patterns for HX-3 wt. \% TiC nanocomposite: (a) bright-field TEM image; (b) EDX point analysis for the precipitate; (c) SAED pattern for the precipitate marked in Fig. 6a; (d) bright-field TEM image taken from the

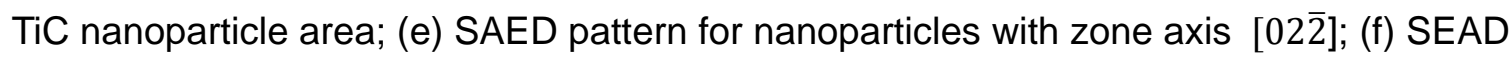

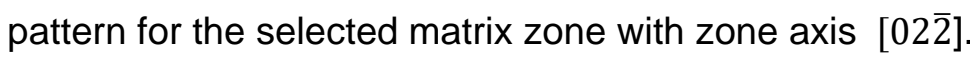

Fig. 8 shows EBSD inverse pore figure mapping and bright-field TEM micrographs of the as-fabricated pure $H X$ and $H X-1$ nanocomposite samples. The $H X-3$ nanocomposite offered similar grain orientations compared to the $\mathrm{HX}-1$ nanocomposite but had more open pores and TiC clusters. The EBSD images for HX3 nanocomposite are not presented in Fig. 8. These images are useful for the investigation of the microcracking-elimination mechanism in the nanocomposite materials. Both materials offered random grain orientations, indicating a relatively weak texture in both materials after the SLM process (Fig. 8a and 8c). The grain size and morphology, however, differed greatly between the two materials: the average length of the columnar grains formed in the pure $\mathrm{HX}$ was greater than $500 \mu \mathrm{m}$, and the maximum value was nearly $1 \mathrm{~mm}$ along the build direction. The grains formed in the HX-1 nanocomposite were much smaller in both the length and width dimensions. The difference in grain structure between pure $\mathrm{HX}$ and $\mathrm{HX}-1$ samples may be 
attributed to two factors. First, the optimal LED to manufacture pure HX was determined to be $52 \mathrm{~J} / \mathrm{mm}^{3}$, while this value was increased to $83 \mathrm{~J} / \mathrm{mm}^{3}$ to fabricate the HX-1 nanocomposite. Since the dimensions of formed grains were positively correlated to thermal gradient, the difference in LED could result in significant differences in thermal gradient in both cases so that the grain structure differed between both samples. Second, the addition of $1 \mathrm{wt} . \%$ TiC nanoparticles might be another contributor for grain structure change in the as-fabricated HX-1 nanocomposite. This is because the added TiC nanoparticles may function as nucleation sites to promote heterogeneous nucleation and further contribute to the grain refinement.

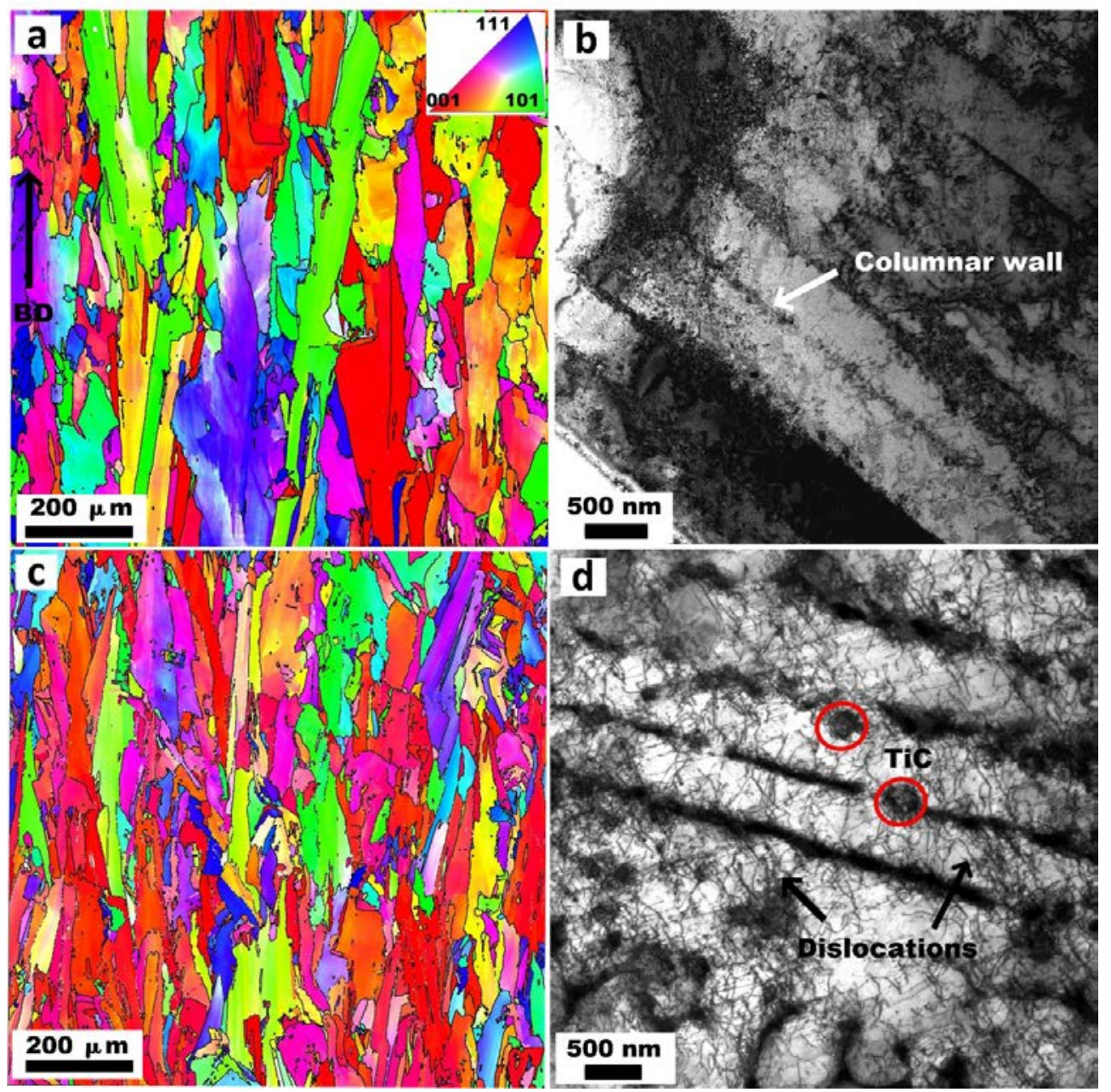

Fig. 8. EBSD and bright-field TEM images for (a)-(b) as-fabricated pure HX alloy; (c)-(d) asfabricated bulk HX-1 wt.\% TiC nanocomposite sample.

Although the majority of the grains still showed a columnar morphology, the average grain length was much smaller in the HX-1 nanocomposite, and a few 
equiaxed grains had also formed compared to the grains formed in pure HX. The significantly increased grain boundaries in the HX-1 nanocomposite enabled a uniform distribution of the strains that had been induced by the accumulated residual thermal stress within the components. The cohesion between adjacent grains may have been enhanced because of the increase in grain boundaries. This increased cohesion partially explains the elimination of microcracking in both the SLM-fabricated HX-1 and HX-3 nanocomposites. Our finding is also consistent with findings from previous studies, which have demonstrated that an increase in high-angle grain boundaries contributes to hot-tearing resistance in the casting of nickel-based superalloys [36][37].

Our study's TEM micrographs clearly show the columnar wall structures in both pure $\mathrm{HX}$ and $\mathrm{HX}-1$ nanocomposite samples; the EDX mapping analysis we conducted had already indicated that the columnar wall structures were surrounded by $\mathrm{M}_{23} \mathrm{C}_{6}$ precipitates (Fig. 7). We should note that the SLM-fabricated HX-1 nanocomposite offered a much higher dislocation density compared to the as-fabricated pure HX. In addition, several uniformly distributed TiC nanoparticles were detected in the bulk HX1 nanocomposite. The mismatch of the coefficient of thermal expansion (CTE) between the $\mathrm{HX}$ matrix and the TiC ceramic nanoparticles was the primary contributor to the significant increase in dislocations. Previous studies have suggested that the contribution of CTE mismatch strengthening is significant in SLM-fabricated nanocomposites because the CTE difference between the matrix and ceramic particles increases with temperature [38][24]. In our study, the entanglements of dislocation lines functioned as pinning points, which hindered the dislocations' motion and could have enhanced the mechanical strength of both the $\mathrm{HX}-1$ and $\mathrm{HX}-3$ nanocomposites materials. In addition, the compressive stress induced by the stress field around the dislocations was capable of counteracting the residual tensile thermal stress, which we consider to have been a significant contributor to microcrack formation.

\subsection{Tensile performance}


Fig. 9 shows the tensile properties of as-fabricated pure $\mathrm{HX}$ and nanocomposite specimens as well as a comparison with various results reported in the literature. Tensile performance was measured using uniaxial tensile testing at room temperature; two specimens for each material were tested to generate the engineering stress-strain curves. The dimensions of the tensile specimens (which were determined based on ASTM guidelines) are also shown in Fig. 9a. Because of the large number of microcracks that formed in the as-fabricated pure HX samples, the tensile behaviours of the two specimens were found to be very consistent, with an ultimate tensile strength (UTS) value of $920 \pm 3 \mathrm{MPa}$; the elongation to failure was determined to be $13 \pm 2 \%$. Due to the microcrack elimination in the HX-1 nanocomposite specimens, significant increases in both UTS and elongation were achieved. The UTS and elongation values were determined to be 1,100 $\pm 4 \mathrm{MPa}$ and $23 \pm 3 \%$, respectively. With an increased TiC content from 1 wt.\% to 3 wt.\%, the HX-3 nanocomposites did not show an apparent increase in tensile strength. A UTS value that was only $\sim 30 \mathrm{MPa}$ higher was obtained in the HX-3 nanocomposites, while a $11 \%$ elongation to failure was sacrificed compared to the HX-1 nanocomposite material.
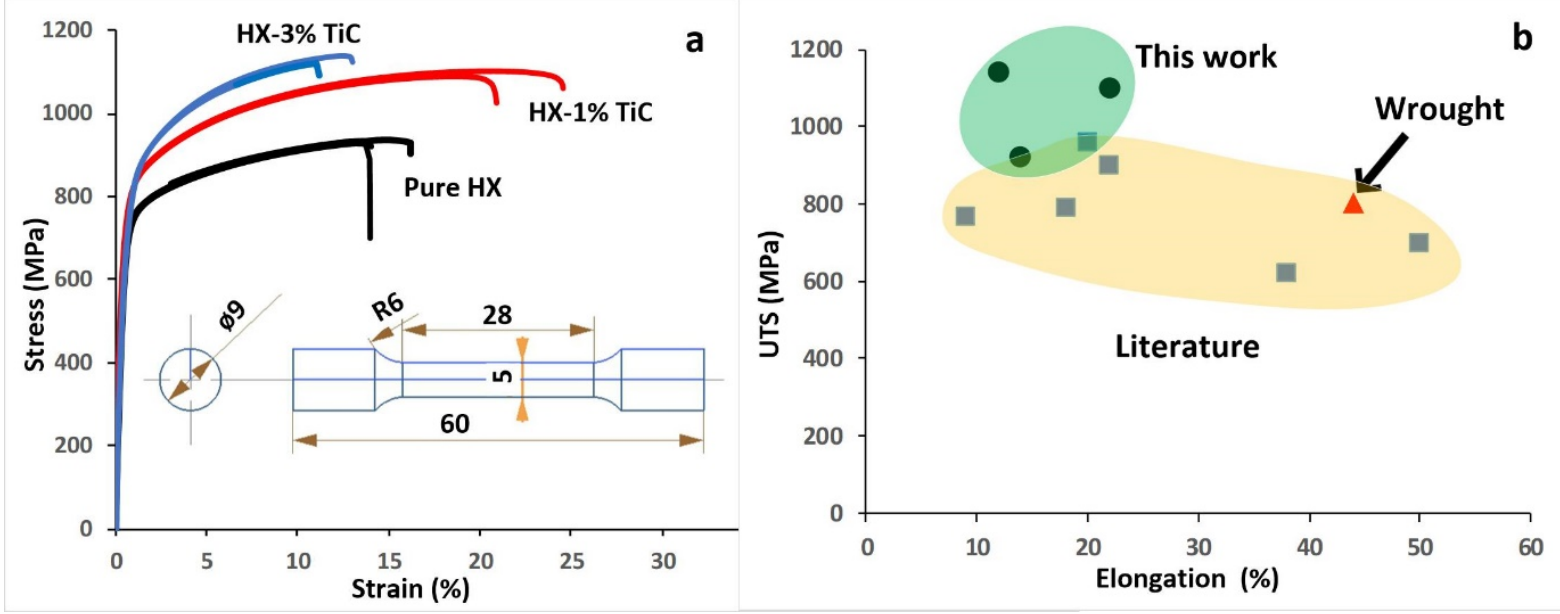

Fig. 9. Tensile performance of the as-fabricated pure HX and nanocomposites materials: (a) the engineering stress-strain curves of pure $\mathrm{HX}, \mathrm{HX}-1$ and $\mathrm{HX}-3$ nanocomposite samples obtained in this study; (b) 'ultimate tensile strength' versus 'elongation to failure' values for $\mathrm{HX}$ alloy reported in the literature [8][19][9][35][39].

A comparison of the tensile performance of the three materials clearly indicates that the SLM-fabricated HX-1 nanocomposite materials exhibited both high-strength and high-ductility behaviours compared to the pure $\mathrm{HX}$ and $\mathrm{HX}-3$ nanocomposites. 
The HX-1 nanocomposites exhibited an over 19\% increase in UTS, which we attribute to the grain refinement and CTE mismatch strengthening compared to pure HX. The $10 \%$ improvement in elongation to failure was more likely to have been caused by the elimination of microcracks. A further increase in TiC content to $3 \mathrm{wt} . \%$ did not contribute further enhancement in tensile strength but did reduce elongation by $\sim 10 \%$. This situation could be explained by the open pores and TiC clusters that formed, which functioned as fracture initiators.

The 'ultimate tensile strength' versus 'tensile elongation to failure' values for $\mathrm{HX}$ materials reported in the present study compared to the literature are shown in Fig. 9b. The SLM-fabricated HX alloys exhibited comparative UTS values, but the elongation-to-failure values were much lower compared to the wrought $\mathrm{HX}$ alloy. Previous studies have reported, however, that SLM-fabricated HX offers over $150 \mathrm{MPa}$ higher yield strength than wrought $\mathrm{HX}$ [9][39]. Due to the successful elimination of microcracks in the present study, the UTS values for both HX-1 and HX-3 nanocomposites we obtained were superior compared to the reported wrought- and SLM-fabricated HX alloy, but the open pores and TiC clusters that formed in the HX3 nanocomposite significantly degraded the material's ductility. We may conclude that the addition of $1 \mathrm{wt} . \%$ TiC nanoparticles enabled the achievement of both high strength and high ductility for the SLM-manufactured HX material. This finding suggests that high-strength and high-ductility performance for the SLM-fabricated materials could be achieved by the selection of suitable reinforcement materials and content. 


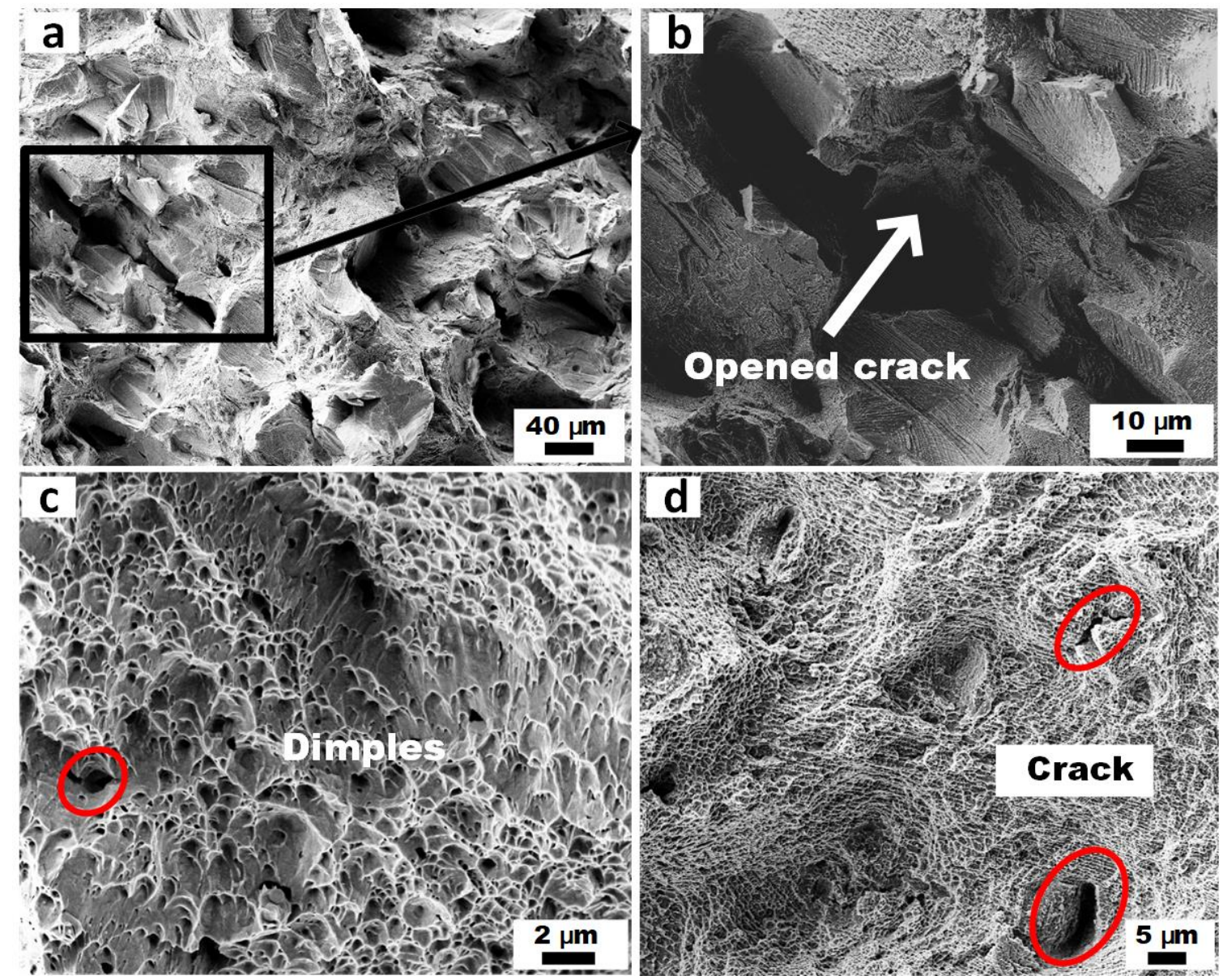

Fig. 10. SEM micrographs showing the fracture surfaces of as-fabricated samples: (a)-(b) pure HX alloy; (c) HX-1 wt.\% TiC nanocomposite; (d) HX-3 wt.\% TiC nanocomposite.

Fig. 10 shows the fracture surfaces of the tensile specimens for the three materials after tensile testing. Although the build direction was perpendicular to the force-loading direction, the microcracks that formed along the build direction in pure $\mathrm{HX}$ were further reopened due to the uniaxial tensile testing (Fig. 10a-b). Typical cleavage-fracture surfaces had formed, suggesting a brittle fracture for the SLM-fabricated pure HX alloy. This finding shows consistency with the stress-strain curves in which a relatively low elongation-to-failure value was determined (13\%, Fig. 9a). Despite the limited number of open pores, $\mathrm{HX}-1$ nanocomposite exhibited a smoother fracture surface with a large number of fine dimples (void size of $<2 \mu \mathrm{m}$ ), indicating a ductile fracture for the asfabricated HX-1 nanocomposite (Fig. 10c).

In addition to open pores, several microcracks formed and were observed on the fracture surfaces of the HX-3 nanocomposite tensile specimens (Fig. 10d). The fracture surfaces were also found to be much coarser compared to the $\mathrm{HX}-1$ 
nanocomposite. We should note that the microcracks that formed in the $\mathrm{HX}-3$ nanocomposite were much smaller than the opened cracks that formed in the pure HX. This situation occurred because the microcracks that formed in the $\mathrm{HX}-3$ nanocomposite were caused by the TiC nanoparticle clusters after rapid solidification; the clusters acted as stress-concentration sites and fracture initiators, which accelerated rupturing during uniaxial tensile testing. This finding shows agreement with the tensile performance we measured in which a relatively low elongation-tofailure value (12\%) was shown in the SLM-fabricated HX-3 nanocomposite.

\section{Conclusions}

This study has investigated the effects of TiC content on the microstructure and tensile performance of Hastelloy $X(\mathrm{HX})$-based nanocomposites manufactured by the selective laser melting (SLM) additive-manufacturing process. The experimental study explored the possible microcracking-elimination mechanism induced by the addition of TiC nanoparticles. The following findings were derived from the experimental results.

(1) The addition of TiC nanoparticles was found to be more influential of effective thermal conductivity compared to laser absorption on the feedstock powder material. The increase in TiC content also led to the extra laser-energy density required to manufacture nearly full-density nanocomposite specimens. The optimal laser-energy densities for manufacturing pure $\mathrm{HX}, \mathrm{HX}-1 \mathrm{wt} \%$ (HX-1) and 3 wt.\% (HX-3) TiC nanocomposites were determined to be 52, 83 and $125 \mathrm{~J} / \mathrm{mm}^{3}$, respectively.

(2) The primary defect in the SLM-fabricated pure $H X$ alloy was found to be microcracking, even under the optimal manufacture condition, although microcracking was eliminated in the SLM-fabricated $\mathrm{HX}-1$ and $\mathrm{HX}-3$ nanocomposite materials. Our detailed EBSD and TEM investigations have indicated that the significantly increased grain boundaries, together with the high dislocation density, were most likely the primary contributors to microcracking elimination.

(3) The addition of $1 \mathrm{wt} \% \mathrm{TiC}$ nanoparticles contributed to the elimination of 
microcracking, with a pore-volume percentage of $0.026 \%$ based on micro-CT examination. Although the addition of $3 \mathrm{wt}$ \% TiC reinforcement also enabled the elimination of microcracking, this addition also resulted in the formation of TiC clusters and a pore-volume percentage of $0.15 \%$ in the SLM-fabricated HX-3 nanocomposite samples.

(4) Compared to SLM-fabricated pure HX alloy, the HX-1 nanocomposite exhibited over $19 \%$ and $10 \%$ improvements in ultimate tensile strength and elongation to failure, respectively. A further increase in TiC content to $3 \mathrm{wt} . \%$, however, was not found to further enhance tensile strength, while $\sim 10 \%$ was lost in elongation. This finding suggests that the added $3 \mathrm{wt} . \%$ TiC nanoparticles very likely went over the threshold of the TiC nanoparticles, such that the Marangoni stress was not strong enough to disperse the TiC nanoparticles within the molten pools.

Our findings demonstrate that the microcracking defect within SLM of Nickel-based $\mathrm{HX}$ alloy can be eliminated by the addition the TiC nanoparticles, which improved both the strength and ductility properties of the manufactured nanocomposites when an optimal content was employed. The overall mechanical performance, however, could be degraded while the TiC reinforcement content goes over the threshold. The present study offers a promising pathway to employ the SLM process to manufacture both high-strength and high-ductility metallic materials that will have practical engineering applications through the careful selection of nanoparticle materials and content.

\section{Acknowledgements}

The lead author gratefully appreciates the financial support of the Qilu Young Scholar Programme (Grant No. 31360082063010), Shandong University, China. The authors wish to thank ASTUTE 2020, a large-scale research programme, funded by the Welsh European Funding Office through the Welsh Government and the participating HE Institutions. The work was also supported by the Advanced Imaging of Materials (AIM) facility (EPSRC Grant No. EP/M028267/1), the Welsh Government Enhancing Competitiveness Grant (MA/KW/5554/19), the European Social Fund (ESF) through the European Union's Convergence programme administered by the Welsh 
Government.

\section{CRediT authorship contribution statement}

Quanquan Han: Conceptualization, Investigation, Writing - Original Draft, Funding acquisition. Yuchen Gu: Validation, Investigation, Resources, Writing - Review \& Editing. Liqiao Wang: Review \& Editing. Qixiang Feng: Conceptualization, Writing Review \& Editing. Heng Gu: Validation, Review. Richard Johnston: Investigation, Writing - Review \& Editing. Rossitza Setchi: Resources, Methodology.

\section{Declaration of interest statement}

The authors have no conflict of interest.

\section{Data availability statement}

The raw/processed data required to reproduce these findings cannot be shared at this time as the data also forms part of an ongoing study.

\section{References}

[1] F. Wang, X.H. Wu, D. Clark, On direct laser deposited Hastelloy X: dimension, surface finish, microstructure and mechanical properties, Mater. Sci. Technol. 27 (2011) 344-356. https://doi.org/10.1179/026708309X12578491814591.

[2] M. Aghaie-Khafri, N. Golarzi, Forming behavior and workability of Hastelloy $X$ superalloy during hot deformation, Mater. Sci. Eng. A. 486 (2008) 641-647. https://doi.org/10.1016/j.msea.2007.11.059.

[3] F. Wang, Mechanical property study on rapid additive layer manufacture Hastelloy?? $X$ alloy by selective laser melting technology, Int. J. Adv. Manuf. Technol. 58 (2012) 545-551. https://doi.org/10.1007/s00170-011-3423-2.

[4] Q. Han, R. Liu, Theoretical model for CNC whirling of screw shafts using standard cutters, Int. J. Adv. Manuf. Technol. 69 (2013) 2437-2444. https://doi.org/10.1007/s00170-013-5214-4.

[5] Z. Sun, X. Tan, S.B. Tor, W.Y. Yeong, Selective laser melting of stainless steel 316L with low porosity and high build rates, Mater. Des. 104 (2016) 197-204. https://doi.org/10.1016/j.matdes.2016.05.035.

[6] D. Buchbinder, H. Schleifenbaum, S. Heidrich, W. Meiners, J. Bültmann, High power Selective Laser Melting (HP SLM) of aluminum parts, in: Phys. Procedia, 2011: pp. 271-278. https://doi.org/10.1016/j.phpro.2011.03.035.

[7] Q. Han, Y. Gu, S. Soe, F. Lacan, R. Setchi, Effect of hot cracking on the mechanical properties of Hastelloy $X$ superalloy fabricated by laser powder bed fusion additive manufacturing, Opt. Laser Technol. 124 (2020) 105984. https://doi.org/10.1016/j.optlastec.2019.105984. 
[8] D. Tomus, Y. Tian, P.A. Rometsch, M. Heilmaier, X. Wu, Influence of post heat treatments on anisotropy of mechanical behaviour and microstructure of Hastelloy-X parts produced by selective laser melting, Mater. Sci. Eng. A. 667 (2016) 42-53. https://doi.org/10.1016/j.msea.2016.04.086.

[9] M.L. Montero-Sistiaga, S. Pourbabak, J. Van Humbeeck, D. Schryvers, K. Vanmeensel, Microstructure and mechanical properties of Hastelloy X produced by HP-SLM (high power selective laser melting), Mater. Des. 105 (2019) 107598. https://doi.org/10.1016/j.matdes.2019.107598.

[10] G. Marchese, G. Basile, E. Bassini, A. Aversa, M. Lombardi, D. Ugues, P. Fino, S. Biamino, Study of the microstructure and cracking mechanisms of hastelloy $X$ produced by laser powder bed fusion, Materials (Basel). 11 (2018) 106. https://doi.org/10.3390/ma11010106.

[11] J.S. Moya, S. Lopez-Esteban, C. Pecharromán, The challenge of ceramic/metal microcomposites and nanocomposites, Prog. Mater. Sci. 52 (2007) 1017-1090. https://doi.org/10.1016/j.pmatsci.2006.09.003.

[12] Z. Zhang, D.L. Chen, Contribution of Orowan strengthening effect in particulatereinforced metal matrix nanocomposites, Mater. Sci. Eng. A. 483 (2008) 148-152. https://doi.org/10.1016/j.msea.2006.10.184.

[13] S.I. Cha, K.T. Kim, S.N. Arshad, C.B. Mo, S.H. Hong, Extraordinary strengthening effect of carbon nanotubes in metal-matrix nanocomposites processed by molecularlevel mixing, Adv. Mater. 17 (2005) 1377-1381.

https://doi.org/10.1002/adma.200401933.

[14] Q. Han, Y. Geng, R. Setchi, F. Lacan, D. Gu, S.L. Evans, Macro and nanoscale wear behaviour of Al-Al2O3 nanocomposites fabricated by selective laser melting, Compos. Part B Eng. 127 (2017) 26-35. https://doi.org/10.1016/j.compositesb.2017.06.026.

[15] X. Yao, S.K. Moon, B.Y. Lee, G. Bi, Effects of heat treatment on microstructures and tensile properties of IN718/TiC nanocomposite fabricated by selective laser melting, Int. J. Precis. Eng. Manuf. 18 (2017) 1693-1701.

[16] D. Gu, H. Zhang, D. Dai, M. Xia, C. Hong, R. Poprawe, Laser additive manufacturing of nano-TiC reinforced Ni-based nanocomposites with tailored microstructure and performance, Compos. Part B Eng. 163 (2019) 585-597. https://doi.org/10.1016/j.compositesb.2018.12.146.

[17] P. Wang, B. Zhang, C.C. Tan, S. Raghavan, Y.F. Lim, C.N. Sun, J. Wei, D. Chi, Microstructural characteristics and mechanical properties of carbon nanotube reinforced Inconel 625 parts fabricated by selective laser melting, Mater. Des. 112 (2016) 290-299. https://doi.org/10.1016/j.matdes.2016.09.080.

[18] R. Wang, W. Wang, G. Zhu, W. Pan, W. Zhou, D. Wang, F. Li, H. Huang, Y. Jia, D. Du, A. Dong, D. Shu, B. Sun, Microstructure and mechanical properties of the TiN particles reinforced IN718C composite, J. Alloys Compd. 762 (2018) 237-245. https://doi.org/10.1016/j.jallcom.2018.05.096.

[19] N.J. Harrison, I. Todd, K. Mumtaz, Reduction of micro-cracking in nickel superalloys processed by Selective Laser Melting: A fundamental alloy design approach, Acta Mater. 94 (2015) 59-68. https://doi.org/10.1016/j.actamat.2015.04.035.

[20] B. Vrancken, S. Dadbakhsh, R. Mertens, K. Vanmeensel, J. Vleugels, S. Yang, J.P. 
Kruth, Selective Laser Melting process optimization of Ti-Mo-TiC metal matrix composites, CIRP Ann. 68 (2019) 221-224. https://doi.org/10.1016/j.cirp.2019.04.120.

[21] B. AlMangour, M.S. Baek, D. Grzesiak, K.A. Lee, Strengthening of stainless steel by titanium carbide addition and grain refinement during selective laser melting, Mater. Sci. Eng. A. 712 (2018) 812-818. https://doi.org/10.1016/j.msea.2017.11.126.

[22] B. AlMangour, D. Grzesiak, T. Borkar, J.M. Yang, Densification behavior, microstructural evolution, and mechanical properties of TiC/316 L stainless steel nanocomposites fabricated by selective laser melting, Mater. Des. 138 (2018) 119128. https://doi.org/10.1016/j.matdes.2017.10.039.

[23] B. AlMangour, D. Grzesiak, J. Cheng, Y. Ertas, Thermal behavior of the molten pool, microstructural evolution, and tribological performance during selective laser melting of TiC/316L stainless steel nanocomposites: Experimental and simulation methods, J. Mater. Process. Technol. 257 (2018) 288-301. https://doi.org/10.1016/j.jmatprotec.2018.01.028.

[24] W.H. Yu, S.L. Sing, C.K. Chua, C.N. Kuo, X.L. Tian, Particle-reinforced metal matrix nanocomposites fabricated by selective laser melting: A state of the art review, Prog. Mater. Sci. 104 (2019) 330-379. https://doi.org/10.1016/j.pmatsci.2019.04.006.

[25] Q. Han, Y. Gu, R. Setchi, F. Lacan, R. Johnston, S.L. Evans, S. Yang, Additive manufacturing of high-strength crack-free Ni-based Hastelloy $X$ superalloy, Addit. Manuf. 30 (2019) 100919. https://doi.org/10.1016/j.addma.2019.100919.

[26] U. Scipioni Bertoli, A.J. Wolfer, M.J. Matthews, J.P.R. Delplanque, J.M. Schoenung, On the limitations of Volumetric Energy Density as a design parameter for Selective Laser Melting, Mater. Des. 113 (2017) 331-340. https://doi.org/10.1016/j.matdes.2016.10.037.

[27] H. Attar, M. Calin, L.C. Zhang, S. Scudino, J. Eckert, Manufacture by selective laser melting and mechanical behavior of commercially pure titanium, Mater. Sci. Eng. A. 593 (2014) 170-177. https://doi.org/10.1016/j.msea.2013.11.038.

[28] C. Ma, J. Zhao, C. Cao, T.C. Lin, X. Li, Fundamental study on laser interactions with nanoparticles-reinforced metals part $i$ : Effect of nanoparticles on optical reflectivity, specific heat, and thermal conductivity, J. Manuf. Sci. Eng. Trans. ASME. 138 (2016) 121001. https://doi.org/10.1115/1.4033392.

[29] X.P. Li, G. Ji, Z. Chen, A. Addad, Y. Wu, H.W. Wang, J. Vleugels, J. Van Humbeeck, J.P. Kruth, Selective laser melting of nano-TiB2decorated AISi10Mg alloy with high fracture strength and ductility, Acta Mater. 129 (2017) 183-193. https://doi.org/10.1016/j.actamat.2017.02.062.

[30] J. Ordonez-Miranda, R. Yang, J.J. Alvarado-Gil, Thermal Conductivity of Particulate Nanocomposites, Springer, 2014. https://doi.org/10.1007/978-3-319-02012-9_3.

[31] O. Sanchez-Mata, J.A. Muñiz-Lerma, X. Wang, S.E. Atabay, M. Attarian Shandiz, M. Brochu, Microstructure and mechanical properties at room and elevated temperature of crack-free Hastelloy $X$ fabricated by laser powder bed fusion, Mater. Sci. Eng. A. 780 (2020) 139177. https://doi.org/10.1016/j.msea.2020.139177.

[32] R. Esmaeilizadeh, A. Keshavarzkermani, U. Ali, Y. Mahmoodkhani, B. Behravesh, H. Jahed, A. Bonakdar, E. Toyserkani, Customizing mechanical properties of additively manufactured Hastelloy $X$ parts by adjusting laser scanning speed, J. Alloys Compd. 
812 (2020) 152097. https://doi.org/10.1016/j.jallcom.2019.152097.

[33] A. Keshavarzkermani, R. Esmaeilizadeh, U. Ali, P.D. Enrique, Y. Mahmoodkhani, N.Y. Zhou, A. Bonakdar, E. Toyserkani, Controlling mechanical properties of additively manufactured hastelloy $X$ by altering solidification pattern during laser powder-bed fusion, Mater. Sci. Eng. A. 762 (2019) 138081. https://doi.org/10.1016/j.msea.2019.138081.

[34] D. Tomus, P.A. Rometsch, M. Heilmaier, X. Wu, Effect of minor alloying elements on crack-formation characteristics of Hastelloy-X manufactured by selective laser melting, Addit. Manuf. 16 (2017) 65-72. https://doi.org/10.1016/j.addma.2017.05.006.

[35] Q. Han, R. Mertens, M. Montero-Sistiaga, S. Yang, R. Setchi, K. Vanmeensel, B. Hooreweder, S.L. Evans, H. Fan, Laser powder bed fusion of Hastelloy X: effects of hot isostatic pressing and the hot cracking mechanism, Mater. Sci. Eng. A. 732 (2018) 228-239. https://doi.org/https://doi.org/10.1016/j.msea.2018.07.008.

[36] Y.Z. Zhou, A. Volek, Effect of grain boundary fraction on castability of a directionally solidified nickel alloy, Scr. Mater. 12 (2006) 2169-2174. https://doi.org/10.1016/j.scriptamat.2006.02.032.

[37] J. Zhang, R.F. Singer, Effect of Grain-Boundary Characteristics on Castability of Nickel-Base Superalloys, Metall. Mater. Trans. A Phys. Metall. Mater. Sci. 35 (2004) 939-946. https://doi.org/10.1007/s11661-004-0018-7.

[38] A. Sanaty-Zadeh, Comparison between current models for the strength of particulatereinforced metal matrix nanocomposites with emphasis on consideration of Hall-Petch effect, Mater. Sci. Eng. A. 531 (2012) 112-118. https://doi.org/10.1016/j.msea.2011.10.043.

[39] X. Ni, D. Kong, L. Zhang, C. Dong, J. Song, W. Wu, Effect of Process Parameters on the Mechanical Properties of Hastelloy X Alloy Fabricated by Selective Laser Melting, J. Mater. Eng. Perform. 28 (2019) 5533-5540. https://doi.org/10.1007/s11665-01904275-w. 